\title{
The future is now: An endovascular option for type A aortic dissection
}

\author{
George J. Arnaoutakis, MD, and Wilson Y. Szeto, MD
}

From the Division of Cardiovascular Surgery, University of Pennsylvania, Philadelphia, Pa.

Disclosures: W.Y. Szeto is on the Consultant/Advisory Board for Micro Interventional Devices, Inc, and received research grants from Edwards Lifesciences Corp, Medtronic, Inc, LivaNova, and Bolton Medical. The other author has nothing to disclose with regard to commercial support.

Received for publication Aug 15, 2016; accepted for publication Aug 15, 2016; available ahead of print Sept 17, 2016.

Address for reprints: Wilson Y. Szeto, MD, Division of Cardiovascular Surgery, Penn Presbyterian Medical Center, University of Pennsylvania Medical Center, $51 \mathrm{~N}$ 39th St, Heart and Vascular Pavillion 2A, Philadelphia, PA 19104 (E-mail: wilson.szeto@uphs.upenn.edu).

J Thorac Cardiovasc Surg 2017;153:S12-3

$0022-5223 / \$ 36.00$

Copyright (C) 2016 by The American Association for Thoracic Surgery

http://dx.doi.org/10.1016/j.jtcvs.2016.08.034

The broad use of endovascular technology to treat descending thoracic aortic pathology has led to interest in applying these technologies to the ascending aorta, with particular emphasis on ascending type A aortic dissection (ATAD). There are several remaining technical challenges that warrant consideration. These include the close proximity between the aortic root, ascending aorta, and aortic arch; the intricate spatial relationships between vital structures of the aortic root; and available device dimensions are currently not designed for the ascending aorta. Published studies on endovascular approaches to the ascending aorta have been limited by relatively small sample size and heterogeneous aortic pathologies. ${ }^{1-3}$

In this study, Nienaber and colleagues ${ }^{4}$ report a multi-institutional, international experience with thoracic endovascular aortic repair (TEVAR) for ATAD. During a 7-year span, they treated 12 patients with ascending TEVAR for ATAD, using a variety of stent graft devices. Six patients had an acute presentation, and 6 patients had a subacute time course before intervention. There was a single operative mortality due to wire-related left ventricular perforation. Otherwise, they achieved procedural success with entry tear exclusion in all remaining cases, and no type I endoleaks were seen during follow-up. Importantly, only 1 minor neurologic event was observed, and there was not a single incidence of stroke. These are excellent results in a patient population with significant comorbid burden of disease, and the study authors should be congratulated.

There are several clinical features of the patient population that are noteworthy. This was an elderly patient cohort, with average age greater than 80 years. Furthermore, all patients had either significant chronic lung disease, coronary disease, or renal dysfunction, and all were symptomatic at presentation. No patient, however, had evidence of aortic insufficiency or distal malperfusion. Most of the patients had a DeBakey type II dissection,

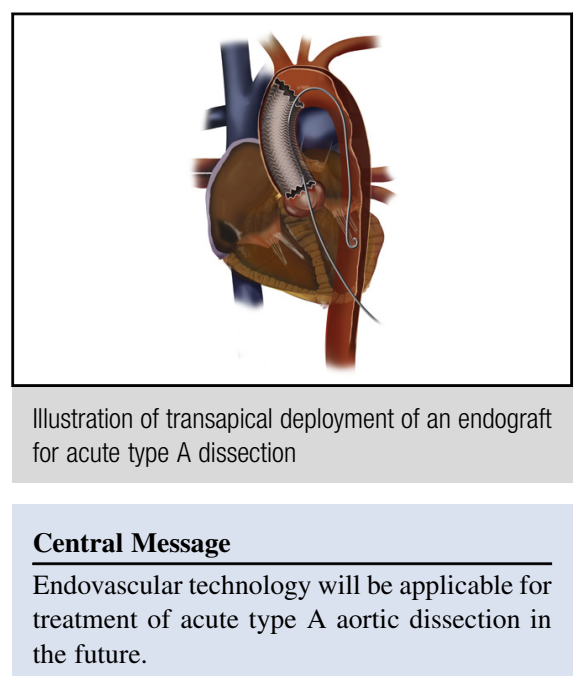

See Article page S3.

which likely explains the fact that there were no distal malperfusion events. Further work is needed to identify the suitability of this strategy in patients who present with severe aortic regurgitation or neurologic sequelae from malperfusion.

This study demonstrates the feasibility of applying TEVAR technology to ascending aortic dissection (Figure 1). The authors also highlight that there is currently an unmet need for a suitable treatment strategy in a large number of patients with ATAD. Approximately $15 \%$ of patients with ATAD are deemed too high risk for conventional open surgical repair, and medical management of these patients has dismal outcomes with greater than $60 \%$ in-hospital mortality. ${ }^{5}$ This population of patients may stand to benefit significantly from TEVAR technology. Furthermore, in a recent report by the International Registry of Acute Aortic Dissection, surgical mortality remains at approximately $20 \% .^{5}$ Although these results have improved over the last 2 decades, we must constantly and critically examine our results and strive to improve outcomes, particularly in patients who present with unstable hemodynamics, contained rupture, or malperfusion. Additional studies with larger sample sizes are needed to identify which patients most stand to benefit from the TEVAR approach.

Technological advancements in cardiothoracic surgery require both new design technology as well as enhancements in existing technology. There has been successful 


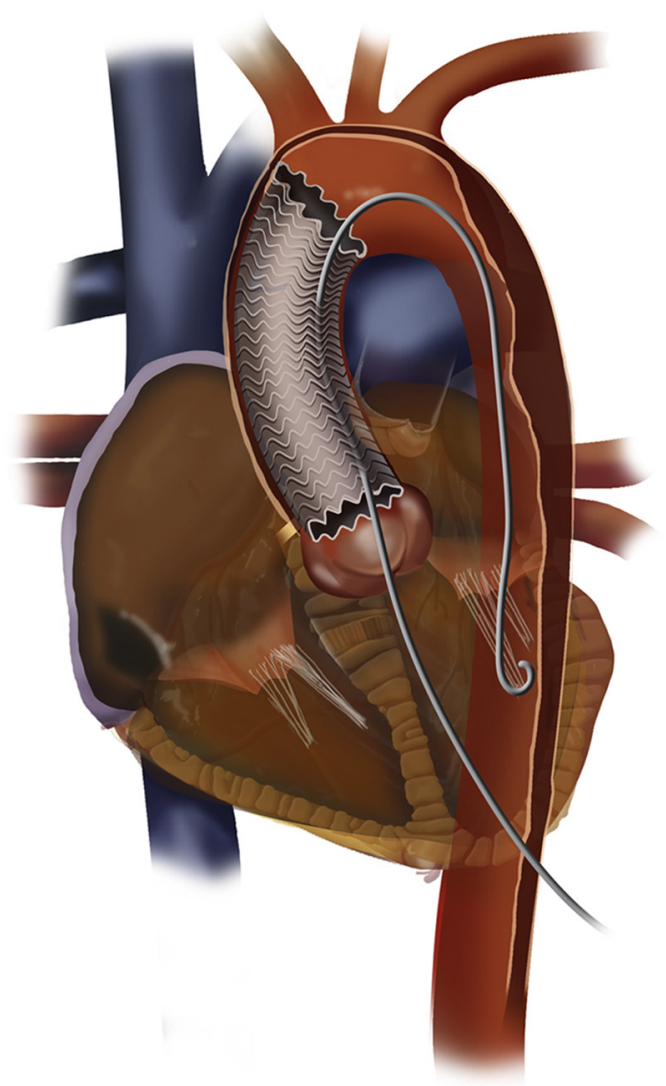

FIGURE 1. Illustration of transapical deployment of an endograft for acute type A dissection.

use of a Zenith device specifically designed for the ascending aorta, but more work needs to be done. ${ }^{6}$ It is imperative that the cardiothoracic surgical community embraces innovation and works jointly with the endovascular technology industry to manufacture disease-specific devices intended for use in the ascending aorta. It is equally important to adopt a multidisciplinary effort, where the concept of an aortic team mirrors the heart team approach currently utilized so successfully in many institutions in the management of structural heart disease. TEVAR should be viewed as a complementary treatment platform to open repair in selected high-risk patients, and not necessarily as a complete replacement to open surgery. Nienaber and colleagues ${ }^{4}$ are to be commended for pushing the envelope forward in the management of this highly lethal disease process.

\section{References}

1. Piffaretti G, Galli M, Lomazzi C, Franchin M, Castelli P, Mariscalco G, et al. Endograft repair for pseudoaneurysms and penetrating ulcers of the ascending aorta. J Thorac Cardiovasc Surg. 2016;151:1606-14.

2. Roselli EE, Idrees J, Greenberg RK, Johnston DR, Lytle BW. Endovascular stent grafting for ascending aorta repair in high-risk patients. J Thorac Cardiovasc Surg. 2015;149:144-51.

3. Vallabhajosyula P, Gottret JP, Bavaria JE, Desai ND, Szeto WY. Endovascular repair of the ascending aorta in patients at high risk for open repair. $J$ Thorac Cardiovasc Surg. 2015;149:S144-50.

4. Nienaber CA, Sakalihasan N, Clough RE, Aboukoura M, Mancuso E, Yeh JSM, et al. Thoracic endovascular aortic repair (TEVAR) in proximal (type A) aortic dissection: Ready for a broader application? J Thorac Cardiovasc Surg. 2017; 153:S3-11.

5. Pape LA, Awais M, Woznicki EM, Suzuki T, Trimarchi S, Evangelista A, et al. Presentation, diagnosis, and outcomes of acute aortic dissection: 17-year trends from the international registry of acute aortic dissection. J Am Coll Cardiol. 2015;66:350-8.

6. Tsilimparis N, Debus ES, Oderich GS, Haulon S, Terp KA, Roeder B, et al. International experience with endovascular therapy of the ascending aorta with a dedicated endograft. J Vasc Surg. 2016;63:1476-82. 